American Journal of Applied Sciences 6 (4): 561-564, 2009

ISSN 1546-9239

(C) 2009 Science Publications

\title{
Nematic and Smectic Mesophase from Calamitic Bisazobenzene Liquid Crystal: Synthesis and Characterization of 1- Methoxyhexyloxy-4 -(4-Phenylazo) Azobenzene Hybrid Molecule
}

\author{
${ }^{1}$ Sidik Silong, ${ }^{1}$ Abdulsalam Abubakar Salisu, ${ }^{1}$ Muhamad Zaki Ab Rahman, \\ ${ }^{2}$ Lutfor Rahman and ${ }^{1}$ Mansor Ahmad \\ ${ }^{1}$ Department of Chemistry, University Putra Malaysia, \\ 43400, Serdang Selangor Darul Ehsan, Malaysia \\ ${ }^{2}$ School of Science, University Malaysia Sabah, \\ Locked Bag 2073, 88999 Kota Kinabalu Sabah, Malaysia
}

\begin{abstract}
A new hybrid calamitic liquid crystal material with rod-shape bisazobenzene moieties as a core has been synthesized and characterized by spectroscopic methods. The mesomorphic properties were investigated by differential scanning colorimetry, polarizing optical microscopy and X-Ray diffraction. The rod-shaped molecule 1- methoxyhexyloxy-4`-(4-phenylazo)azobenzene was prepared by diazotization of 4-phenylazoaniline, coupling with phenol and subsequent etherification of 1Bromohexyloxy-4 -(4-phenylazo)azobenzene in methanol. The presence of enantiotropic nematic and smectic A mesophases were confirmed by the textures and X-Ray diffraction.
\end{abstract}

Key words: Liquid crystal, bisazobenzene, calamitic, nematic phase, smectic phase

\section{INTRODUCTION}

Liquid Crystals (LCs) are fascinating state of matter having certain properties characteristics of liquid with other typical of crystals. Thermotropic liquid crystals exhibit mesomorphic behavior within a specific temperature range. They are either discotic, having planar, disc-like molecules or calamitic, having cylinder-shaped rod-like molecules ${ }^{[1,2]}$.

The mesophases of thermotropic LCs are thermodynamically stable but only partially ordered phases. Each mesophase is described by its degree of order. If the mesophase has orientational order only, it is called nematic $(\mathrm{N})$, if it has both orientational and positional order it is called smectic (Sm). The nematic liquid crystal phase is technologically the most important mesophase. It is used in almost all commercially available LC displays. On the other hand, the smectic LC phases have found very little commercially successful applications. Most of the known thermotropic LCs are calamitic structurally ${ }^{[1-6]}$. A calamitic mesogen molecule consists of a core, terminal chains and lateral substituents. The core provides rigidity which is required for anisotropy, whereas the terminal chains provide flexibility to stabilize the molecular alignment within the mesophase.
The core is usually a linearly linked aromatic ring system. The rings can be directly linked or they may be joined by a linking group.

The terminal chains are either, straight alkyl or alkoxy chains, one terminal unit is often a polar substituent. These calamitic molecules form both nematic and smectic mesophases depending upon the type of the substituents and their combinations ${ }^{[1,2]}$.

It is well known that photochromic molecules such as azobenzenes can undergo a reversible photochemical reaction between two forms trans-cis photoisomerization; The trans form of the azobenzene, with a rod-like shape, stabilizes the phase structure of the LC, while the bent cis form tends to destabilize the phase structure. These properties have enabled LCs containing azobenzene chromospheres to be widely used in display technologies and various photonic applications, including optical storage, optical switching, optical computers and integrated optical devices for communication ${ }^{[10]}$. The level of photoinduced birefringence was shown to depend strongly on the type and size of azobenzene groups ${ }^{[8]}$. The photoinduced birefringence per azobenzene structure in bisazobenzene-based polymers was five times larger and more stable than that in azobenzene polymers $^{[9,10]}$.

Corresponding Author: Sidik bin Silong, Department of Chemistry, Universiti Putra Malaysia, 43400 UPM Serdang, Selangor, Malaysia Tel: +603-98466808 Fax: +603-98435088 
We report here in this contribution, a new calamitic liquid crystal molecule consisting of bisazobenzene rigid core with methoxyhexyloxy terminal chain given rise to new hybrid based calamitic liquid crystal molecule.

\section{MATERIALS AND METHODS}

All materials are of analytical grade unless otherwise stated. 4-phenylazoaniline (Fluka), Sodium nitrite (BDH), Urea (BDH), Phenol (Merck), 1,6dibrohexane (Fluka), potassium carbonate (Fluka), potassium hydroxide (Fluka), methanol (Merck) were used as received. Dry acetone was obtained from distilling over phosphorous pentoxide (Merck). Other solvent and chemicals were used without further purification.

Techniques: The structures of the intermediates and the final product were confirmed by spectroscopic methods: FT-IR spectra were measured on a Spectrum BX II FT-IR spectrophotometer (Perkin Elmer). ${ }^{1} \mathrm{H}$ NMR spectra $(400 \mathrm{MHz})$ were recorded on a JEOL ECA 400 spectrometer (JEOL, Japan). Mass Spectra was obtained on Shimadzu QP5050A (Shimadzu, Japan). Phase transition temperatures and thermodynamic parameters were determined by using a DSC 7 (Perking Elmer) equipped with a liquid nitrogen cooling system under nitrogen atmosphere and the heating and cooling rates were $10^{\circ} \mathrm{C} \mathrm{min}^{-1}$. Phase transition temperatures were collected during the second heating and the second cooling scans. Phase identification was performed by polarized light microscopy using an Olympus BX50 (Japan) polarizing optical microscope (OPM) equipped with a Linkam THMSE-600 (Linkam, England) hot stage and a TMS 92 control unit. The X-Ray measurements were performed using a nickel-filtered $\mathrm{Cu}-\mathrm{K}_{\alpha 1}$ radiation with X-Ray Difractometer PANalytical X'Pert-Pro MPD PW3040/60 XRD.

\section{RESULTS AND DISCUSSION}

Figure 1 shows the structures and our synthetic approach to the calamitic bisazobenzene molecule. The bisazobenzene core part was prepared by diazotization of a well known powerful dye, 4-phenylazoaniline and then coupling of the resulting diazonium salt, with phenol yielding 4-hydroxy-4`-(4-phenylazo) azobenzene 2 .

The flexible spacer was introduced by alkylation of phenol 2, with a 10-fold excess of 1,6- dibromohexane in the presence of potassium carbonate as base and catalytic amount of potassium iodide to give 1Bromohexyloxy-4`-(4-phenylazo)azobenzene 3 according to a similar procedure reported in the literature ${ }^{[7]}$.

The final compound 4, 1-methoxyhexyloxy-4`-(4phenylazo)azobenzene was produced by further reaction with methanol in presence of potassium hydroxide and a typical procedure for compound 4 is as follows:

1-methoxyhexyloxy-4 -(4-phenylazo)azobenzene 4: Compound 3 1-Bromohexyloxy-4`-(4-phenylazo-) azobenzene $(0.5 \mathrm{~g}, \quad 0.001 \mathrm{M})$ potassium hydroxide $(0.191 \mathrm{~g}, 0.003 \mathrm{M})$ was heated to reflux in methanol $(80$ $\mathrm{mL}$ ) for $8 \mathrm{hrs}$ under nitrogen atmosphere. The reaction mixture was filtered hot and allowed to cool to room temperature, then poured into acidified $(10 \% \mathrm{HCl})$ icecold water. The resulting precipitate was collected by filtration and purified by column chromatography on silica gel with chloroform/methanol (9:1); as eluant.
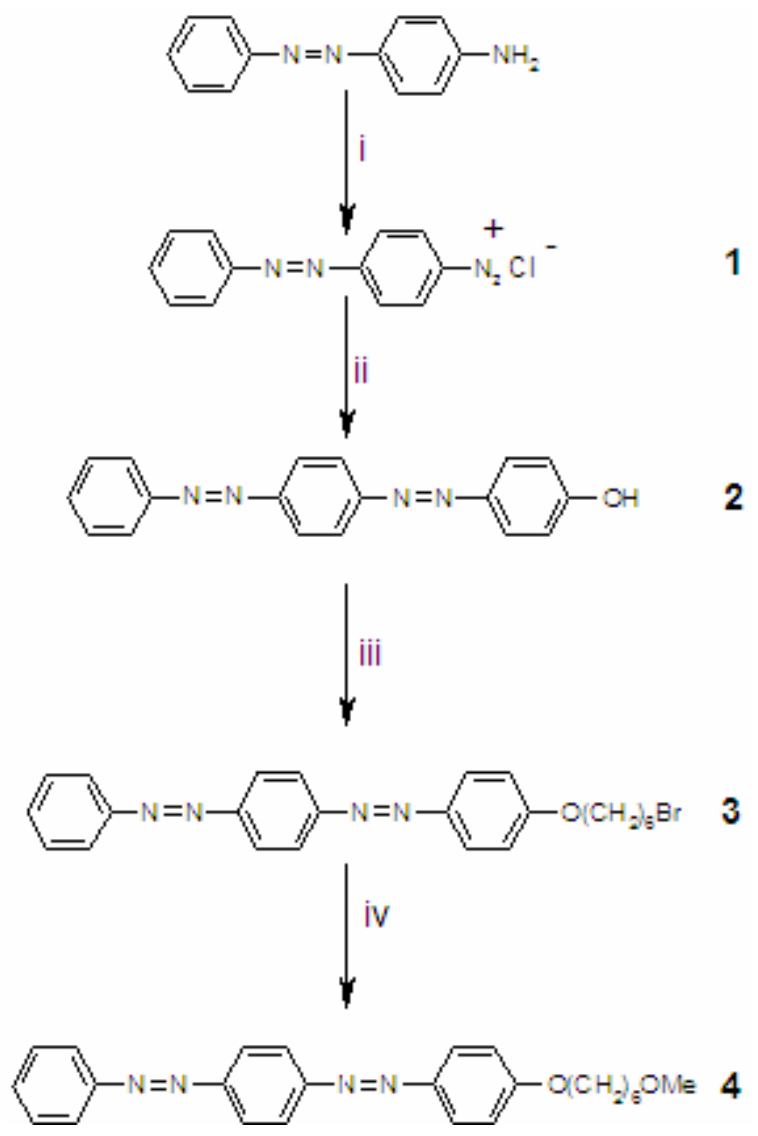

Fig. 1: Reactions and conditions: (i) $\mathrm{NaNO}_{2} / \mathrm{HCI}$; (ii) Phenol, $2^{\circ} \mathrm{C}$; (iii) $\mathrm{Br}\left(\mathrm{CH}_{2}\right)_{6} \mathrm{Br}$ (iv) $\mathrm{MeOH}$, $\mathrm{KOH}$ 
Table 1: Phase transition temperatures and enthalpies obtained from DSC scans of $4^{\mathrm{a}}$

Transition temperature $\left(\mathrm{T} /{ }^{\circ} \mathrm{C}\right)$ and associated transition enthalpies values $\left(\Delta \mathrm{H} \mathrm{Jg}^{-1}\right)$

2nd Heating

Cr 99.34 (59.5) SmA133.19 (2.9) N152.20 (1.4)I

2nd Cooling

I149.31 (1.23) N129.15 (2.7) SmA61.19 (43.1)Cr

a: Abbreviations; $\quad \mathrm{Cr}=$ Crystal; $\mathrm{SmA}=$ Smectic $\mathrm{A} ; \mathrm{N}=$ Nematic; $\mathrm{I}=$ Isotropic phase

The solid was crystallized from methanol and ethanol respectively. Yield $42 \%$, m.p. $102-107^{\circ} \mathrm{C}$. Elemental analysis: Found C 72.09, H 6.78, N 13.45; Calculated for $\left(\mathrm{C}_{25} \mathrm{H}_{28} \mathrm{~N}_{4} \mathrm{O}_{2}\right), \mathrm{C} 72.01 \mathrm{H} \mathrm{6.63}, \mathrm{N} \mathrm{13.36;} \mathrm{MS} \mathrm{m/z}$ $416\left(\mathrm{M}^{+}\right)$; IR, $\left(\mathrm{KBr}, \mathrm{cm}^{-1}\right): 2938,2862(\mathrm{C}-\mathrm{H}, \mathrm{v}), 1602$, 1584, 1498, 1474 (aromatic, v), $1394(\mathrm{C}-\mathrm{H}, \delta), 1250$, $1148(\mathrm{C}-\mathrm{H}, \delta), 856$ (aromatic, $\delta) .{ }^{1} \mathrm{H}$ NMR $(400 \mathrm{MHz}$, $\left.\mathrm{CDCl}_{3}\right) \delta: 8.05(2 \mathrm{H}, \mathrm{d}, \mathrm{ArH}), 8.05$ (4H, dd, $\left.\mathrm{ArH}\right), 7.96$ $(2 \mathrm{H}, \mathrm{t}, \mathrm{ArH}) 7.53(2 \mathrm{H}, \mathrm{d}, \mathrm{ArH}), 7.25(1 \mathrm{H}, \mathrm{z}, \mathrm{ArH}), 7.02$ $(2 \mathrm{H}, \mathrm{d}, \mathrm{ArH}), 7.00(2 \mathrm{H}, \mathrm{d}, \mathrm{ArH}) 4.10\left(2 \mathrm{H}, \mathrm{t}, \mathrm{OCH}_{2}\right)$, $3.45\left(2 \mathrm{H}, \mathrm{d}, \mathrm{OCH}_{2}\right) 3.34\left(3 \mathrm{H}, \mathrm{s}, \mathrm{OCH}_{3}\right), 1.84(2 \mathrm{H}, \mathrm{s}$, $\left.\mathrm{CH}_{2}\right), 1.57\left(2 \mathrm{H}, \mathrm{s}, \mathrm{CH}_{2}\right), 1.46\left(2 \mathrm{H}, \mathrm{m}, \mathrm{CH}_{2}\right) 1.44(2 \mathrm{H}, \mathrm{s}$, $\left.\mathrm{CH}_{2}\right) ;{ }^{13} \mathrm{C}$ NMR $\left(400 \mathrm{MHz} \mathrm{CDCl}_{3}\right) \delta: 26.04,29.00$, $29.12,29.57,58.57,68.26,72.73,114.78,122.99$, $123.41,123.75,125.05,129.12,131.27,147.00,152.73$, $153.30,153.98,162.00$.

Phase transitions: The phase transition temperatures as well as the phase transition enthalpy changes were determined using Differential Scanning Calorimetry (DSC) and the result of the second heating and second cooling scans are shown in Table 1. The material is very stable crystal at room temperature and exhibit enantiotropic phase behavior

On heating from room temperature to isotropic liquid, three endothermic peaks were observed. The DSC thermogram of compound 4 is shown in Fig. 2. Three exothermic peaks were found on cooling from the isotropic liquid. The enthalpy change at the SmA-N transition is higher than at the N-Iso transition which is usually observed for this type of phase transition ${ }^{[5]}$.

Phase structures: The phase structures were determined by Optical Polarizing Microscope (OPM). The polarized optical micrograph of 4 , observed for the two mesophases in the liquid crystalline phase during the second heating and cooling cycle, is shown in Fig. 3a and b. On heating to the isotropic phase, a focalconic fan texture of smectic A was observed under the optical polarizing microscope at $134.2^{\circ} \mathrm{C}$. On further heating a schlieren texture, as typical for nematic phase was observed at $152.8^{\circ} \mathrm{C}$. On cooling from the isotropic phase a schlieren texture, as typical for nematic phases,

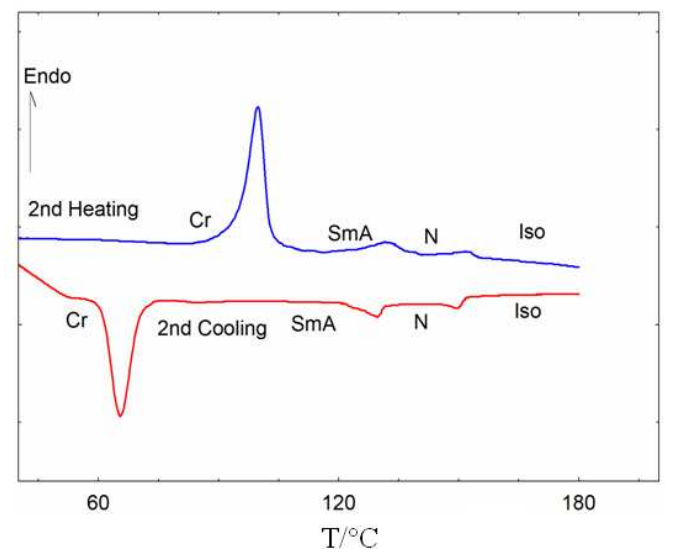

Fig. 2: DSC heating and cooling traces of compound $4\left(10^{\circ} \mathrm{C} \min ^{-1}\right)$
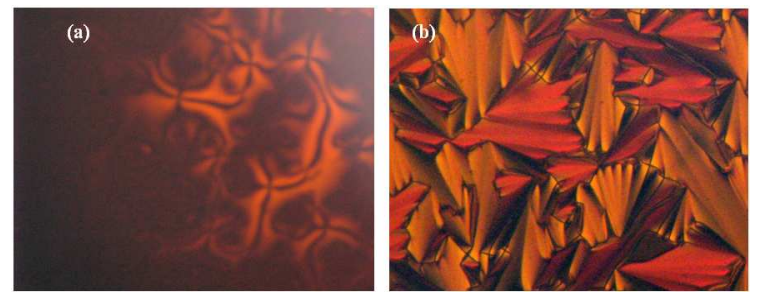

Fig. 3: Optical photomicrograph of 4 obtained with a polarizing microscope (a): On cooling from the isotropic liquid at $149.2^{\circ} \mathrm{C}(\mathrm{b})$ : On cooling from the nematic phase $128.7^{\circ} \mathrm{C}$ (Cross polarizer magnification $\times 200$ )

also appeared at 149.6 Fig. 3a. This nematic is highly fluid and upon further cooling a well-defined texture, Fan-shaped focal conic texture appeared at $128.7^{\circ} \mathrm{C}$ Fig. 3b.

This texture is a characteristic for Smectic A phases and remained stable up to $78.5^{\circ} \mathrm{C}$. Shearing leads to a homoetropic alignment, which appeared optically isotropic There is no further phase transition on further cooling until it crystallized at $61.7^{\circ} \mathrm{C}$. This mesophase behavior shows that the two azobenzene chromophores have the same conformational (trans-) direction in the liquid crystal state since, according to $\mathrm{Yu}$ and Ikeda azobenzene liquid crystals show a liquid crystal phase only when the azobenzene moieties are in the trans- form and they never show a liquid crystal phase at any temperature when all of the azobenzene moieties are in the cis- form ${ }^{[10]}$.

X-ray diffraction: The Smectic structure of the liquid crystal phase is confirm by XRD studies. The X-ray pattern of the Smectic A recorded at $120^{\circ} \mathrm{C}$ contains a 
diffused band at $4.48 \AA(2 \theta=20.67)$ (wide angle), which shows that the alkyl chains have a liquid-like structure and are segregated from the aromatic core. It is obvious that a smectic layer structure exists; no mixed reflections were found at the low angle region $47.34 \AA\left(2 \theta=4.24^{\circ} \mathrm{C}\right)$. There was no additional reflection that can be seen at the small angle region.

\section{CONCLUSION}

A new calamitic liquid crystal molecule based on bisazobenzene core connected to six alkylene units with methoxy group at the terminal has been prepared. The material is an enantiotropic molecule exhibiting smectic A and nematic phases. The core length (extended bisazobenzene), absence of lateral groups on the bisazobenzene core and the presence of methoxy group at terminal end were observed to improve the enantiotropic behavior, thermal and mesophase stability of the compound.

\section{ACKNOWLEDGEMENT}

This study was supported by the department of chemistry, Universiti Putra Malaysia and the Malaysian government, especially the ministry of Science, Technology and Innovation for providing facilities and Research Grand No. 04-01-04-SF0144 Sincere thanks goes to the Bayero University Kano, Nigeria for offering study fellowship, McArthur Grant No. 82511 and Kano state Government of Nigeria for financial assistance

\section{REFERENCES}

1. KılıÇ M. and Z. Çınar, 2007. Structures and mesomorphic properties of cyano-containing calamitic liquid crystal molecules. J. Mol. Struct., 808:53-61.

http://cat.inist.fr/?aModele=afficheN\&cpsidt=18685024.

2. Gray, G.W., 1987. Thermotropic Liquid Crystals. 1st Edn., John Wiley and Sons, New York, pp: $1-22$.
3. Kim, J.H., V. Vorflusev and S. Kumar, 2004. Single glass substrate LCDs using a phase separated composite organic film method. Displays, 25: 207-213 DOI: 10.1016/j.displa.2004.09.011.

4. Kuo, W.H., P.H. Lin and S.L. Hwang, 2007. A framework of perceptual quality assessment on LCD-TV. Displays, 28: 35-43. http://cat.inist.fr/?aModele=afficheN\&cpsidt=18526972.

5. Hsieh, K.L., 2008. The application of clustering analysis for the critical areas on TFT-LCD panel. Expert Syst. Appl.: Int. J., 34: 952-957. DOI: 10.1016/j.eswa.2006.10.035.

6. Hsu, H.F., H.C. Chen, C.H. Kuo, B.C. Wang and H.T. Chiu, 2005. Design and investigation of calamitic liquid crystals with low aspect ratios: Rigid y-shaped 1,2,4-tris (4-alkoxyphenylethynyl) benzenes. J. Mater. Chem., 15: 4854-4861. http://cat.inist.fr/?aModele=afficheN\&cpsidt=17310381.

7. Lutfor, M.R., M. Yusoff, C. Tshierske, K. Pel, U. Baumeister and S. Sidik, 2005. Nematic and smectic mesophase formation by a novel tripphenylene azobenzene hybride molecule. http://www.e-lc.org/Documents/1119836839.pdf.

8. Zheng, Z., L. Wang, Z. Su, J. Xua, J. Yang and Q. Zhang, 2007. Photoinduced chirality in achiral liquid crystalline poly- methacrylates containing bisazobenzene and azobenzene chromophores. J. Photochem. Photobio. A. Chem., 185: 338-344. http://cat.inist.fr/?aModele=afficheN\&cpsidt=18421332.

9. Cojocariu, C. and P. Rochon, 2005. Thermotropic side-chain liquid crystalline copolymers containing both mono- and bisazobenzene mesogene: Synthesis and properties. Macromolecules, 38: 9526-9538. DOI: $10.1021 / \mathrm{ma} 051455 \mathrm{~h}$.

10. Yu, Y. and Y. Ikeda, 2004. Thermotropic sidechain liquid crystalline copolymers containing both mono- and bisazobenzene mesogens: Synthesis and properties. J. Photochem. Photobio. C: Photochem. Rev., 5: 247-265. 